\title{
Review of Health Problems in Adult Patients with Classic Congenital Adrenal Hyperplasia due to 21-Hydroxylase Deficiency
}

\author{
Author \\ Nicole Reisch
}

\section{Affiliation}

Medizinische Klinik IV, Klinikum der Universität München, München

\section{Key words}

congenital adrenal hyperplasia, 21-hydroxylase deficiency, adrenal androgens, adrenal crisis, fertility, testicular adrenal rest tumour, cardiovascular risk, bone health

\section{Bibliography}

DOI https://doi.org/10.1055/a-0820-2085

Exp Clin Endocrinol Diabetes 2019; 127: 171-177

(c) J. A. Barth Verlag in Georg Thieme Verlag KG Stuttgart . New York

ISSN 0947-7349

Correspondence

Nicole Reisch

Medizinische Klinik IV

Klinikum der Universität München

Ziemssenstraße 1

80336 München

Tel: + 49(0)894400 52111

Nicole.reisch@med.uni-muenchen.de

\begin{abstract}
The introduction of newborn screening programmes in most Western countries for classic congenital adrenal hyperplasia due to 21-hydroxylase deficiency (CAH) enables timely introduction of life-saving glucocorticoid replacement in affected babies. Early diagnosis and optimised pediatric care not only successfully led to survival but also allow that almost all patients reach adulthood. Cohort studies in adults, however, provided evidence for significant health problems and co-morbidities of adult patients such as life-threatening adrenal crises, cardiovascular and metabolic health problems, fertility problems, benign endocrine tumours, and osteopenia and osteoporosis. This review summarises the current state of knowledge aiming to emphasize the neccessity of primary and secondary prevention of additional long-term health issues as a major task of health professionals in the care of $\mathrm{CAH}$.
\end{abstract}

Congenital adrenal hyperplasia (CAH) is a group of autosomal recessive disorders resulting in glucocorticoid insufficiency [1]. The vast majority of cases is caused by 21-hydroxylase deficiency (21OHD). Steroid $11 \beta$-hydroxylase deficiency accounts for only $5-8 \%$ of $\mathrm{CAH}$ cases, other enzymatic defects causing $\mathrm{CAH}$ as $17 \alpha$-hydroxylase deficiency, $3 \beta$-hydroxysteroid dehydrogenase type 2 , steroidogenic acute regulator protein, P450 cholesterol side-chain cleavage enzyme or P450 oxidoreductase deficiency are extremely rare. The impaired cortisol synthesis in classic 21-OHD leads to a loss of negative feedback on the hypothalamic and pituitary level, thereby increasing ACTH driving adrenal androgen excess and adrenal hyperplasia. In most Western countries newborn screening programmes aim to detect the severe form, the so called classic 21-hydroxylase deficiency and therefore incidences are known to be $1: 10,000$ to $1: 15,000$ [2-4]. Classic 21-OHD is defined by clinically glucocorticoid deficiency and is subclassified in the simple -virilising or salt-wasting form in case of additional mineralocorticoid deficiency. The mild, non-classic form, is more frequent found affecting about 1:2000 [5]. The latter is characterised by adrenal androgen excess, however, usually without clinically relevant cortisol deficiency. ( $\triangleright$ Table $\mathbf{1}$ )

Since the 1950ies life-saving glucocorticoid replacement therapy has become available enabling longterm survival of classic $\mathrm{CAH}$ patients. Thus, the oldest patients with this condition are in their late sixties. However, timely correct diagnosis has been difficult and before the introduction of Newborn Screening programmes often overlooked. As a consequence many patients presumably died from salt wasting crises in their first few weeks of life. Therefore most patients are still at a young age, most adult patient cohorts are on average in their thirties.

We therefore have become aware of the long-term consequences and outcome of classic CAH patients only recently.

Despite optimised diagnosis, life-saving glucocorticoid and mineralocorticoid replacement therapy, the patients struggle with a variety of comorbidities affecting their health-related quality of life. Current glucocorticoid replacement therapies cannot mimic circadian cortisol rhythmicity nor stress-related glucocorticoid increase. It is a real therapeutic challenge to strike the right balance of gluco- 
- Table 1 Checklist for surveillance of long-term health problems in adult patients with classic 21-OHD. Adapted from Reisch N, Arlt W., Congenital Adrenal Hyperplasia. In: Oxford Desk Reference Endocrinology Oxford: Oxford University Press, 2018: 221-224.

\begin{tabular}{|c|c|}
\hline To do: & Interval \\
\hline $\begin{array}{l}\text { Biochemistry/Endocrine laboratory: } \\
\text { 17-hydroxyprogesterone, androstenedione, } \\
\text { testosterone (SHBG), progesterone, estradiol, } \\
\text { LH, FSH, Sodium, Potassium, Renin }\end{array}$ & Annually \\
\hline $\begin{array}{l}\text { Physcial examination: Body mass index, blood } \\
\text { pressure, acne, hirsutism, striae, hyperpigmen- } \\
\text { tation, Cushingoid features }\end{array}$ & Annually \\
\hline $\begin{array}{l}\text { Stress dosing: Adrenal crisis since last review? } \\
\text { Stress dosing of hydrocortisone for illness since } \\
\text { last review? Steroid emergency card? } \\
\text { Knowledge of sick day rules? Glucocorticoid } \\
\text { injection kit for emergency use available? Are } \\
\text { the patient and/or parent/partner/guardian } \\
\text { educated on parenteral self-administration of } \\
\text { emergency glucocorticoids? }\end{array}$ & At least annually \\
\hline Genetic assessment and counselling & $\begin{array}{l}\text { Once at transition and } \\
\text { when fertility is } \\
\text { planned }\end{array}$ \\
\hline Female fertility: Gynaecological assessment & $\begin{array}{l}\text { Once at transition and } \\
\text { then as required, as } \\
\text { recommended in the } \\
\text { general female } \\
\text { population }\end{array}$ \\
\hline $\begin{array}{l}\text { Male fertility: Testicular ultrasound (check for } \\
\text { presence of testicular adrenal rest tumours) }\end{array}$ & $\begin{array}{l}\text { Once at transition, } \\
\text { thereafter according to } \\
\text { findings }\end{array}$ \\
\hline $\begin{array}{l}\text { Cardiovascular health: Fasting lipid profile, } \\
\text { HOMA IR, } 24 \mathrm{~h} \text { ambulatory blood pressure, } \\
\text { refer to counseling with regard to healthy } \\
\text { lifestyle }\end{array}$ & If clinically justified \\
\hline Bone health: BMD & $\begin{array}{l}\text { In patients with } \\
\text { non-traumatic fractures } \\
\text { and with higher } \\
\text { glucocorticoid dosing } \\
\text { and/or long-acting } \\
\text { glucocorticoids }\end{array}$ \\
\hline \multicolumn{2}{|l|}{$\begin{array}{l}\text { Mental health: Consider referral to psycholo- } \\
\text { gical or psychiatric treatment for behavioral/ } \\
\text { mental health consultation and evaluation to } \\
\text { address any concerns related to } 21-\mathrm{OHD}\end{array}$} \\
\hline $\begin{array}{l}\text { Adrenal nodules: No routine adrenal imaging, } \\
\text { only in patients with poor disease control, with } \\
\text { lack of response to intensified therapy, with } \\
\text { history of periods without treatment }\end{array}$ & \\
\hline
\end{tabular}

corticoid dosing. Both, under- as well as overtreatment cause side effects and complications. In order to control adrenal androgens, however, often supraphysiological glucocorticoid doses need to be given. Impaired fertility is of importance for the patients. Several groups showed impaired health status in 21-OHD [6], as well as impaired survival [7]. The main causes of death have found to be adrenal crises and cardiovascular comorbidities highlighting these aspects of the disease [7].

\section{Adrenal Crises}

All patients with the classic form of 21-OHD suffer from glucocorticoid deficiency and thus are at risk for life-threatening adrenal crises life-long. There is no generally agreed definition of adrenal crisis, which is defined as a situation when the increased demand in circulating cortisol cannot be met. Based on the current knowledge and experience and previous definitions of adrenal crisis Rushworth et al.[8] have suggested the following definition: "an acute deterioration in health that is associated with an absolute (systolic blood pressure $(\mathrm{BP})<100 \mathrm{mmHg}$ ) or relative (systolic BP $<20 \mathrm{mmHg}$ lower than usual) hypotension, the features of which resolve following parenteral glucocorticoid administration (marked resolution of hypotension within $1 \mathrm{~h}$ and improvement of clinical symptoms over $2 \mathrm{~h})$ ". Other typical clinical findings comprise dehydration, salt-wasting (hyponatremia and hyperkalemia), hypoglycaemia or altered mental status. Patients present with weakness, vomiting, abdominal pain of confusion. If left untreated it is life-threatening leading to shock, coma and ultimately death. Severe symptomatic hypoglycemic events mainly seem to be a problem in the pediatric population not any longer in adulthood [9]. They may be caused by a lack of cortisol at night. In addition hypoglycaemia may be caused by adrenomedullary dysfuction [10].

Infections or injuries are the most common precipitating factors of adrenal crisis. As children are more prone for infectious diseases, the incidence of adrenal crises is highest in childhood [11]. In a pediatric study based on data extracted from a populationbased prospective long-term follow-up study of children detected in neonatal screening in Southern Germany the incidence of adrenal crises in childhood was 6.5 per 100 patient years [9]. This correlates well with our own data showing an incidence of adrenal crisis over lifetime of 5.8 per 100 patients years, with the highest incidence during childhood and substantially lower incidence of adrenal crises in adulthood [11]. Transition has been shown to be the second vulnerable period predisposing 21-OHD patients for adrenal crises [11]. The main triggers of adrenal crises in this study in $\mathrm{CAH}$ patients were respiratory and gastrointestinal infections [11]. So far it is not clear which patients are predisposed for experiencing multiple adrenal crises. Bancos et al. [12] have shown that primary adrenal insufficiency is associated with impaired natural killer cell function potentially causing a weakened immune defence contributing to an increased rate of infections and adrenal crises. Another study also found a pro-inflammatory state in patients with primary adrenal insufficiency on conventional glucocorticoid replacement therapy [13]. Switching from conventional glucocorticoid replacement twice or thrice daily to a once daily modified-release hydrocortison preparation normalised the immune cell profile and reduced intercurrent infections [13]. At this stage, however, it is not entirely clear if the observed effects are due to the more physiologic circadian glucocorticoid rhythm by the modified release formulation or simply due to an overall dose reduction of glucocorticoid replacement by modified-release formulations and might as well be observed on a reduced dose of conventional glucocorticoids. Further research on the interactions among glucocorticoid deficiency, adrenomedullary dysfunction, and immune cells is necessary for a better understanding of the pathophysiology and the prevention of adrenal crises. 
Prevention of adrenal crises remains a permanent challenge. Expert care, education in stress dosing and emergency recommendations as well as equipment is essential and considered the best approach to prevent adrenal crises. However, adrenal crises may even occur in well educated patients with excellent knowledge of preventive strategies [14-16]. Despite intensive education, patients may still hesitate to implement stress dosing, in particular if parenteral use is necessary and thus is not sufficiently effective. In Germany a standardized patient education programme for patients with adrenal insufficiency and a special part for patients with $\mathrm{CAH}$ has been developed. However, so far the education relies entirely on the commitment of the physicians as it is not reimbursed by health care insurances. Patient support groups are extremely helpful in providing educational material and organising educational programmes.

Swedish data revealed that adrenal crises also are the most frequent cause of death in patients with 21-OHD, not only before the introduction of newborn screening [7]. This study was designed as a matched case-control study with 588 patients with 21-OHD from the national $\mathrm{CAH}$ or patient registry compared 58800 controls from national population-based registers. It is also the first study to show an increased mortality in 21-OHD. Thus, management of adrenal crisis remains a major challenge in the care of $\mathrm{CAH}$ patients and more research is needed to fully understand causes and develop better prevention strategies.

\section{Cardiovascular Morbidities}

The Swedish population-based study [7] identified cardiovascular events as the second most important cause of death in CAH patients. This is the first study to show increased morbidity and mortality and not only increased risk factors, thus emphasizing the importance of cardiovascular prevention in $\mathrm{CAH}$. Several studies have shown increased cardiovascular risk factors in 21-OHD [17-24]. The major cardiovascular risk factor in $\mathrm{CAH}$ seems to be overweight and obesity [20]. Obesity was identified already a major problem in pediatric cohorts $[25,26]$. In adult cohorts even more than half of the female patients were found to be obese [20]. However, there is also data from France showing that body weight is not substantially different in CAH from the general population [23, 27], also an American cohort study showed a similar obesity rate (one third) in $\mathrm{CAH}$ compared to the general population [24]. Investigation of body composition in $\mathrm{CAH}$ shows that overall and abdominal body fat is increased [28]. Few studies also showed a high prevalence of the metabolic syndrome in $\mathrm{CAH}[24,29]$. Studies investigating blood pressure show conflicting results with either normal $[18,21$, 30,31 ] or elevated blood pressure [32]. There are several studies in young cohorts with a trend towards high blood pressure (diurnal of nocturnal) indicating that blood pressure needs to be monitored and may become a more prevalent problem at a higher age [20, 32-37]. Interestingly, a French cohort of male CAH patients showed rather low blood pressure compared with healthy controls [27]. Fludrocortisone and glucocorticoid overexposure contributes to elevated blood pressure and needs to be avoided. In adrenal insufficiency recent studies show an improved metabolic risk profile in patients on modified release hydrocortisone compared to conventional glucocorticoid replacement regimens [13, 38-41].
Blood glucose and body weight seem to improve with a more physiologic circadian cortisol day profile reducing the glucocorticoid exposure in particular in the afternoon by about $20 \%$ [41]. Overtreatment by glucocorticoids and mineralocorticoids on the one hand have detrimental effects on the cardiovascular risk profile in $\mathrm{CAH}[42,43]$, undertreatment with the consequence of adrenal hyperandrogenism on the other hand induces impaired insulin insensitivity $[44,45]$.

The Swedish population based study also showed an increased prevalence of hyperlipidemia, diabetes, venous thromboembolism and atrial fibrillation [46]. Morphology of the left ventricle has been reported as normal $[21,30]$. In CAH women QT interval duration was shorter than in controls [47]. In summary, many studies indicate that $\mathrm{CAH}$ is associated with higher cardiovascular and metabolic risk factors and morbidity. However, patients included in these cohorts are young, thus cardiovascular events and morbidity only is beginning to be characterized. Clearly, these data implicate the responsibility of monitoring cardiovascular and metabolic risk factors and keeping a close eye on the glucocorticoid and mineralocorticoid dosis with regular re-evaluation also in adulthood.

\section{Bone Health}

Bone health is impaired in both males and females in CAH [1]. The prevalence of osteopenia and osteoporosis even in young adults from an age of 40 onwards is increased compared to controls. Some studies even reported an increased fracture risk [48]. The main risk for low bone mass density is chronic glucocorticoid excess [49]. Current replacement regimens all cannot mimic circadian glucocorticoid rhythm irrespective of the formula used, e. g. hydrocortisone, prednisolone or dexamethasone, and all lead to several phases of overtreatment during the day. Even in an attempt to best mimic circadian rhythms with thrice of four times daily hydrocortisone dosing with the highest dose in the early morning and lower doses at midday and in the afternoon, overdosing of about $20 \%$ compared to physiological cortisol day profiles occurs in the afternoon [41]. Due to its higher glucocorticoid potency prednisolone is associated with lower bone mineral density in patients with adrenal insufficiency $[50,51]$. Most cohort studies could not show a direct link of the glucocorticoid dose equivalent to the degree of reduced bone mineral density. This most likely is rather a methodological problem as retrospective data on glucocorticoid doses are often not exact and there is no prospective longterm study on glucocorticoid dose and bone health. Recent studies show normal bone mineral density, when not using glucocortidoids in excessive doses [49, 51]. A particular problem in males is hypogonadotrophic hypogonadisms that can be caused by both over- and undertreatment [52]. On the one hand an excess of adrenal androgens being converted to estrogens can suppress the pituitary-gonadal axis, on the other hand excess glucocorticoids may cause hypogonadotrophic hypogonadism with detrimental effects on bone mineral density [53]. Therefore it seems that males are even more affected by osteopenia or osteoporosis than women, in whom undertreatment with androgen excess rather protects them from loss of bone mineral density. 


\section{Mental Health}

Population-based studies from Sweden showed that the incidence of psychiatric disorders in females and males with 21-OHD is increased $[6,54]$. In females in particular the risk of alcohol abuse was increased with the highest risk in the most severe null genotype. On the contrast, in males, psychiatric morbidity seems not to be raised in the more severe genotypes. A Swedish study also investigated criminal behaviour in $\mathrm{CAH}$ but did not find any increased risk for crime [55]. Interestingly, 21-OHD carriers had a lower risk of developing psychiatric disorders, affective disorders or substance misuse [56]. In this study having a child with 21-OHD was assessed as a psychological stressor and the incidence of psychiatric diagnoses before and after the birth of the child were investigated and compared to the general population and parents with a child with hypospadias or diabetes mellitus type 1 .

\section{Female Fertility and Pregnancy Rate}

The number of pregnancies is significantly reduced in women with $\mathrm{CAH}$, however, pregnancies themselves are commonly normal and uneventful [57-59]. Reduced female fertility is the result of multiple factors including, anovulation, the effects of genital surgery, reduced heterosexual partnership and progesterone hypersecretion. The expression of these factors is related to the severity of the steroid 21-hydroxylase mutation so that child rate is particularly poor in the salt-wasting group $[60,61]$. In the simple virilising form, additional mineralocorticoid replacement therapy may be beneficial for conception [62]. In the CAHase study $20 \%$ of patients had primary and $21 \%$ secondary amenorrhea [20]. Menstrual cycle disturbances have been shown to be more frequent in patients with altered LH pulsatility [63], emphasising the importance of optimal hormonal control, in particular suppression of serum progesterone. Fertility is only mildly reduced in non-classic CAH although two studies found that an increased miscarriage rate in non-classical $\mathrm{CAH}$ normalises with glucocorticoid treatment $[64,65]$.

The endocrine aspects of fertility can be normalised resulting in a normal pregnancy rate [66]. A study from the UK reported that $91.3 \%$ of patients with classic $\mathrm{CAH}$ who tried to become pregnant were successful, however, most patients never tried to conceive (only 23 out of 106 women in the study). Thus, this study showed the same pregnancy rate in $\mathrm{CAH}$ patients as in the normal population and no difference between the salt-wasting and the simple virilising form [66]. Suppression of testosterone hyperscretion and resulting anovulation is relatively simple to achieve. In addition, hypersecretion of progesterone of adrenal origin despite suppressed 17-alpha-hydroxyprogesterone is present in a subgroup of patients, which has to be specifically addressed in order to achieve normal endometrial responsiveness [67]. A normal pregnancy rate can be achieved only with the suppression of follicular phase progesterone to $<2 \mathrm{nmol} / \mathrm{L}$ as a result of increased glucocorticoid doses [66]. In exceptional cases, where progesterone concentrations were impossible to normalise, adrenalectomy has been shown to successfully result in spontaneous conception [68].

Other underlying causes for poor fertility in females with classic $\mathrm{CAH}$ include unsatisfactory intercourse due to inadequate vaginal introitus and a higher rate of homosexuality [69]. Vaginoplasty is performed in about $90 \%$ of infants with $\mathrm{CAH}$, the timing of surgery remains a matter of debate [70-72]. The outcome of genital surgery certainly is a key factor for fertility outcome as vaginal function and sexual activity are closely related. Surgical techniques have changed over time, outcome of sexual function will take time to emerge $[73,74]$. Cosmetic outcomes of genitoplasty have been rated good to excellent in 151 patients in a recent review [70], other data report unsatisfactory results $[20,75]$. In contrast to testicular adrenal rest tumours in males, ovarian adrenal rest tumours as underlying cause for infertility in females seem to be rare [76-79]. For fertility and pregnancy monitoring all females with CAH should see an endocrinologist and a gynaecologist.

\section{Male Fertility}

Several studies found significantly impaired fecundity in males with classic CAH [27, 52, 80, 81]. The CaHase study showed that $37 \%$ $(24 / 65)$ of males had sought fertility and $67 \%$ (16/24) had been successful [20]. Three main factors contribute to male infertility in $\mathrm{CAH}$, adrenal androgen excess driving gonadotrophin suppression, excessive ACTH drive resulting testicular adrenal rest tumours (TART) and testicular failure which can follow on from TART formation.

TART formation results in secondary gonadal dysfunction due to obstruction of the seminiferous tubules. These tumours can be observed in prepubertal children and tumour number and size increase with age $[82,83]$. Their prevalence has been reported between $0-94 \%[52,81]$. The tumours have been shown to be responsive to ACTH-suppressive glucocorticoid therapy with dexamethasone resulting in tumour shrinkage and restoration of sperm counts and fertility $[84,85]$. Effective treatment of TART generally requires therapeutic doses of $0.75 \mathrm{mg}$ dexamethasone per day. This dose typically leads to substantial side effects and therefore it is only recommended as short-term treatment in order to achieve fertility. Whilst the glucocorticoid responsiveness of the tumours suggests an association with disease control, so far no study could show this. Moreover, TART even have been observed in overtreated patients as indicated by suppressed ACTH levels [52, 81, 83, 86], showing that undertreatment is not the only cause of TART. Molecular characterization of TART has shown not only the expression of adrenal cortex markers but also Leydig cell markers, potentially explaining why most TART evolve after puberty [87]. Surgical treatment of TART is no longer advised as it offers no benefit and probably results in additional testicular damage [88]. Treatment options are therefore limited to optimising hormonal control. A recent study also showed that mitotane, used in adrenal cortex cancer, can restore fertility in CAH patients with TART [89]. Inhibin B may serve as an additional marker to FSH and $\mathrm{LH}$ in monitoring and optimising fecundity. Inhibin B differs significantly in patients with and without TART and correlate with sperm concentrations [27].

Importantly, glucocorticoid overdosing can also result in reduced fecundity due secondary hypogonadism [52]. Furthermore, suppression of gonadotrophins by adrenal androgen excess (aromatised to estrogens) because of poor disease control may lead to infertility. In such a case replacement of gonadotrophins may restore fertility [90]. Fertility issues therefore openly need to be discussed with the patients and cryoconservation of sperm offered [91]. 


\section{Adrenal Tumors}

It could be shown that adrenal volume correlates well with disease control markers and in poor disease control large adrenal tumors can be found $[86,92]$. Also myelolipomas are associated with 21-OHD and can be of huge size, requiring removal for mass effect [93]. However, there is no study showing increased malignant potential of these adrenal nodules.

\section{Summary}

Patients with CAH face multiple health risks and problems during adult life which become increasingly evident. Many of these problems most likely are associated with suboptimal glucocorticoid therapy. It seems obvious that current glucocorticoid regimen cannot mimick circadian cortisol secretion and research into more physiologic glucocorticoid replacement and novel therapeutic options is necessary. Monitoring of cardiovascular risk factors needs to be part of the regular follow-up visits of these patients. Furthermore, future research should aim at a better understanding of interindividual vulnerability to adrenal crises in order to develop optimised prevention strategies. With regard to TART, fertility and pregnancy, future investigations will help to define optimal management recommendations.

\section{Acknowledgments}

This work was supported by the Deutsche Forschungemeinschaft (Heisenberg Professorship 325768017 and within the CRC/Transregio 205/1 'The Adrenal: Central Relay in Health and Disease' to N.R.)

\section{Conflict of Interest}

No conflict of interest has been declared by the authors.

\section{References}

[1] El-Maouche D, Arlt W, Merke DP. Congenital adrenal hyperplasia. Lancet 2017; 390: 2194-2210. doi:10.1016/S0140-6736(17)31431-9

[2] Therrell BL, Adams J. Newborn screening in North America. J Inherit Metab Dis 2007; 30: 447-465

[3] Coulm B, Coste J, Tardy V et al. Efficiency of neonatal screening for congenital adrenal hyperplasia due to 21-hydroxylase deficiency in children born in mainland France between 1996 and 2003. Arch Pediatr Adolesc Med 2012; 166: 113-120

[4] Odenwald B, Dorr HG, Bonfig W et al. Classic congenital adrenal hyperplasia due to 21-hydroxylase-deficiency: 13 Years of neonatal screening and follow-up in bavaria. Klin Padiatr 2015; 227: 278-283. doi:10.1055/s-0035-1554639

[5] Carmina E, Dewailly D, Escobar-Morreale HF et al. Non-classic congenital adrenal hyperplasia due to 21-hydroxylase deficiency revisited: An update with a special focus on adolescent and adult women. Hum Reprod Update 2017; 23: 580-599. doi:10.1093/humupd/dmx014

[6] Falhammar H, Butwicka A, Landen M et al. Increased psychiatric morbidity in men with congenital adrenal hyperplasia due to 21-hydroxylase deficiency. J Clin Endocrinol Metab 2014; 99: E554-E560

[7] Falhammar H, Frisen L, Norrby $C$ et al. Increased mortality in patients with congenital adrenal hyperplasia due to 21 -hydroxylase deficiency. J Clin Endocrinol Metab 2014; jc20142957
[8] Rushworth RL, Torpy DJ, Falhammar H. Adrenal crises: Perspectives and research directions. Endocrine 2017; 55: 336-345. doi:10.1007| s12020-016-1204-2

[9] Odenwald B, Nennstiel-Ratzel U, Dorr HG et al. Children with classic congenital adrenal hyperplasia experience salt loss and hypoglycemia: Evaluation of adrenal crises during the first 6 years of life. Eur ] Endocrinol 2016; 174: 177-186. doi:10.1530/EJE-15-0775

[10] Kim MS, Ryabets-Lienhard A, Bali B et al. Decreased adrenomedullary function in infants with classical congenital adrenal hyperplasia. J Clin Endocrinol Metab 2014; 99: E1597-E1601. doi:10.1210/jc.2014-1274

[11] Reisch N, Willige M, Kohn D et al. Frequency and causes of adrenal crises over lifetime in patients with 21-hydroxylase deficiency. Eur J Endocrinol 2012; 167: 35-42

[12] Bancos I, Hazeldine J, Chortis $\vee$ et al. Primary adrenal insufficiency is associated with impaired natural killer cell function: A potential link to increased mortality. Eur J Endocrinol 2017; 176: 471-480. doi:10.1530/EJE-16-0969

[13] Isidori AM, Venneri MA, Graziadio C et al. Effect of once-daily, modified-release hydrocortisone versus standard glucocorticoid therapy on metabolism and innate immunity in patients with adrenal insufficiency (DREAM): A single-blind, randomised controlled trial. Lancet Diabetes Endocrinol 2018; 6: 173-185. doi:10.1016/ S2213-8587(17)30398-4

[14] Allolio B. Extensive expertise in endocrinology. Adrenal crisis. Eur ] Endocrinol 2015; 172: R115-R124. doi:10.1530/EJE-14-0824

[15] Hahner S, Hemmelmann N, Quinkler M et al. Timelines in the management of adrenal crisis - targets, limits and reality. Clin Endocrinol (Oxf) 2015; 82: 497-502. doi:10.1111/cen.12609

[16] Hahner S, Spinnler C, Fassnacht $M$ et al. High incidence of adrenal crisis in educated patients with chronic adrenal insufficiency: A prospective study. J Clin Endocrinol Metab 2015; 100: 407-416. doi:10.1210/jc.2014-3191

[17] Mooij CF, van Herwaarden AE, Sweep F et al. Cardiovascular and metabolic risk in pediatric patients with congenital adrenal hyperplasia due to 21 hydroxylase deficiency. J Pediatr Endocrinol Metab 2017; 30: 957-966. doi:10.1515/jpem-2017-0068

[18] Sartorato P, Zulian E, Benedini S et al. Cardiovascular risk factors and ultrasound evaluation of intima-media thickness at common carotids, carotid bulbs, and femoral and abdominal aorta arteries in patients with classic congenital adrenal hyperplasia due to 21-hydroxylase deficiency. J Clin Endocrinol Metab 2007; 92: 1015-1018

[19] Bachelot A, Plu-Bureau G, Thibaud E et al. Long-term outcome of patients with congenital adrenal hyperplasia due to 21-hydroxylase deficiency. Horm Res 2007; 67: 268-276

[20] Arlt W, Willis DS, Wild SH et al. Health status of adults with congenital adrenal hyperplasia: A cohort study of 203 patients. J Clin Endocrinol Metab 2010; 95: 5110-5121

[21] Falhammar H, Filipsson H, Holmdahl G et al. Metabolic profile and body composition in adult women with congenital adrenal hyperplasia due to 21-hydroxylase deficiency. J Clin Endocrinol Metab 2007; 92: 110-116

[22] Ozdemir R, Korkmaz HA, Kucuk M et al. Assessment of early atherosclerosis and left ventricular dysfunction in children with 21-hydroxylase deficiency. Clin Endocrinol (Oxf) 2017; 86: 473-479. doi: $10.1111 /$ cen. 13275

[23] Bachelot A, Golmard JL, Dulon J et al. Determining clinical and biological indicators for health outcomes in adult patients with childhood onset of congenital adrenal hyperplasia. Eur ] Endocrinol 2015; 173: 175-184. doi:10.1530/EJE-14-0978

[24] Finkielstain GP, Kim MS, Sinaii N et al. Clinical characteristics of a cohort of 244 patients with congenital adrenal hyperplasia. J Clin Endocrinol Metab 2012; 97: 4429-4438

[25] Volkl TM, Simm D, Beier C et al. Obesity among children and adolescents with classic congenital adrenal hyperplasia due to 21-hydroxylase deficiency. Pediatrics 2006; 117: e98-e105 
[26] Sarafoglou K, Forlenza GP, Yaw Addo O et al. Obesity in children with congenital adrenal hyperplasia in the Minnesota cohort: Importance of adjusting body mass index for height-age. Clin Endocrinol (Oxf) 2017; 86: 708-716. doi:10.1111/cen.13313

[27] Bouvattier C, Esterle L, Renoult-Pierre P et al. Clinical outcome, hormonal status, gonadotrope axis, and testicular function in 219 adult men born with classic 21-hydroxylase deficiency. a french national survey. J Clin Endocrinol Metab 2015; 100: 2303-2313. doi:10.1210/jc.2014-4124

[28] Kim MS, Ryabets-Lienhard A, Dao-Tran A et al. Increased abdominal adiposity in adolescents and young adults with classical congenital adrenal hyperplasia due to 21-hydroxylase deficiency. J Clin Endocrinol Metab 2015; 100: E1153-E1159. doi:10.1210/jc.2014-4033

[29] Moreira RP, Villares SM, Madureira G et al. Obesity and familial predisposition are significant determining factors of an adverse metabolic profile in young patients with congenital adrenal hyperplasia. Horm Res Paediatr 2013; 80: 111-118. doi:10.1159/000353762

[30] Mooij CF, Kroese JM, Claahsen-van der Grinten HL et al. Unfavourable trends in cardiovascular and metabolic risk in paediatric and adult patients with congenital adrenal hyperplasia? Clin Endocrinol (Oxf) 2010; 73: 137-146

[31] Ubertini G, Bizzarri C, Grossi A et al. Blood pressure and left ventricular characteristics in young patients with classical congenital adrenal hyperplasia due to 21-hydroxylase deficiency. Int J Pediatr Endocrinol 2009; 2009: 383610. doi:10.1155/2009/383610

[32] Subbarayan A, Dattani MT, Peters Cl et al. Cardiovascular risk factors in children and adolescents with congenital adrenal hyperplasia due to 21-hydroxylase deficiency. Clin Endocrinol (Oxf) 2014; 80: 471-477. doi:10.1111/cen.12265

[33] de Silva KS, Kanumakala S, Brown J] et al. 24-hour ambulatory blood pressure profile in patients with congenital adrenal hyperplasia-a preliminary report. J Pediatr Endocrinol Metab 2004; 17: 1089-1095

[34] VolkI TM, Simm D, Dotsch J et al. Altered 24-hour blood pressure profiles in children and adolescents with classical congenital adrenal hyperplasia due to 21-hydroxylase deficiency. J Clin Endocrinol Metab 2006; 91: 4888-4895

[35] Nermoen I, Bronstad I, Fougner KJ et al. Genetic, anthropometric and metabolic features of adult Norwegian patients with 21-hydroxylase deficiency. Eur J Endocrinol 2012; 167: 507-516. doi:10.1530/EJE-12-0196

[36] Mooij CF, Kroese JM, Sweep FC et al. Adult patients with congenital adrenal hyperplasia have elevated blood pressure but otherwise a normal cardiovascular risk profile. PLoS One 2011; 6: e24204. doi:10.1371/journal.pone.0024204

[37] Roche EF, Charmandari E, Dattani MT et al. Blood pressure in children and adolescents with congenital adrenal hyperplasia (21-hydroxylase deficiency): A preliminary report. Clin Endocrinol (Oxf) 2003; 58: 589-596

[38] Jones CM, Mallappa A, Reisch N et al. Modified-release and conventional glucocorticoids and diurnal androgen excretion in congenital adrenal hyperplasia. J Clin Endocrinol Metab 2017; 102: 1797-1806. doi:10.1210/jc.2016-2855

[39] Mallappa A, Sinaii N, Kumar P et al. A phase 2 study of Chronocort, a modified-release formulation of hydrocortisone, in the treatment of adults with classic congenital adrenal hyperplasia. J Clin Endocrinol Metab 2015; 100: 1137-1145 doi:10.1210/jc.2014-3809

[40] Quinkler M, Miodini Nilsen R, Zopf K et al. Modified-release hydrocortisone decreases $\mathrm{BMI}$ and $\mathrm{HbA} 1 \mathrm{c}$ in patients with primary and secondary adrenal insufficiency. Eur J Endocrinol 2015; 172: 619-626. doi:10.1530/EJE-14-1114

[41] Johannsson G, Nilsson AG, Bergthorsdottir R et al. Improved cortisol exposure-time profile and outcome in patients with adrenal insufficiency: A prospective randomized trial of a novel hydrocortisone dual-release formulation. J Clin Endocrinol Metab 2012; 97: 473-481. doi:10.1210/jc.2011-1926
[42] Fuller P], Young MJ. Mechanisms of mineralocorticoid action. Hypertension 2005; 46: 1227-1235. doi:10.1161/01. HYP.0000193502.77417.17

[43] Pivonello R, Isidori AM, De Martino MC et al. Complications of Cushing's syndrome: State of the art. Lancet Diabetes Endocrinol 2016; 4: 611-629. doi:10.1016/S2213-8587(16)00086-3

[44] Rosenfield RL, Ehrmann DA. The pathogenesis of polycystic ovary syndrome (pcos): The hypothesis of pcos as functional ovarian hyperandrogenism revisited. Endocr Rev 2016; 37: 467-520. doi:10.1210/er.2015-1104

[45] Saygili F, Oge A, Yilmaz C. Hyperinsulinemia and insulin insensitivity in women with nonclassical congenital adrenal hyperplasia due to 21-hydroxylase deficiency: the relationship between serum leptin levels and chronic hyperinsulinemia. Horm Res 2005; 63: 270-274

[46] Falhammar H, Frisen L, Hirschberg AL et al. Increased cardiovascular and metabolic morbidity in patients with 21-hydroxylase deficiency: a swedish population-based national cohort study. J Clin Endocrinol Metab 2015; 100: 3520-3528. doi:10.1210/JC.2015-2093

[47] Abehsira G, Bachelot A, Badilini F et al. Complex influence of gonadotropins and sex steroid hormones on qt interval duration. J Clin Endocrinol Metab 2016; 101: 2776-2784. doi:10.1210/jc.2016-1877

[48] Falhammar $\mathrm{H}$, Filipsson $\mathrm{H}$, Holmdahl $\mathrm{G}$ et al. Fractures and bone mineral density in adult women with 21-hydroxylase deficiency. J Clin Endocrinol Metab 2007; 92: 4643-4649

[49] Schulz ], Frey KR, Cooper MS et al. Reduction in daily hydrocortisone dose improves bone health in primary adrenal insufficiency. Eur J Endocrinol 2016; 174: 531-538. doi:10.1530/EJE-15-1096

[50] Frey KR, Kienitz T, Schulz et al. Prednisolone is associated with a worse bone mineral density in primary adrenal insufficiency. Endocr Connect 2018; 7: 811-818. doi:10.1530/EC-18-0160

[51] Koetz KR, Ventz M, Diederich $S$ et al. Bone mineral density is not significantly reduced in adult patients on low-dose glucocorticoid replacement therapy. J Clin Endocrinol Metab 2012; 97: 85-92

[52] Reisch N, Flade L, Scherr M et al. High prevalence of reduced fecundity in men with congenital adrenal hyperplasia. J Clin Endocrinol Metab 2009; 94: 1665-1670

[53] Reisch N, Arlt W, Krone N. Health problems in congenital adrenal hyperplasia due to 21-hydroxylase deficiency. Horm Res Paediatr 2011; 76: 73-85

[54] Engberg H, Butwicka A, Nordenstrom A et al. Congenital adrenal hyperplasia and risk for psychiatric disorders in girls and women born between 1915 and 2010: A total population study. Psychoneuroendocrinology 2015; 60: 195-205. doi:10.1016/j.psyneuen.2015.06.017

[55] Ohlsson Gotby A, Nordenstrom A, Falhammar H et al. Congenital adrenal hyperplasia, polycystic ovary syndrome and criminal behavior: A Swedish population based study. Psychiatry Res 2015; 229: 953-959. doi:10.1016/j.psychres.2015.07.008

[56] Nordenstrom A, Butwicka A, Linden Hirschberg A et al. Are carriers of CYP21A2 mutations less vulnerable to psychological stress? A population-based national cohort study. Clin Endocrinol (Oxf) 2017; 86: 317-324. doi:10.1111/cen. 13242

[57] Krone N, Wachter I, Stefanidou M et al. Mothers with congenita adrenal hyperplasia and their children: Outcome of pregnancy, birth and childhood. Clin Endocrinol (Oxf) 2001; 55: 523-529

[58] Lo JC, Grumbach MM. Pregnancy outcomes in women with congenita virilizing adrenal hyperplasia. Endocrinol Metab Clin North Am 2001; 30: 207-229

[59] Gastaud F, Bouvattier C, Duranteau L et al. Impaired sexual and reproductive outcomes in women with classical forms of congenital adrenal hyperplasia. J Clin Endocrinol Metab 2007; 92: 1391-1396

[60] Jaaskelainen J, Hippelainen M, Kiekara O et al. Child rate, pregnancy outcome and ovarian function in females with classical 21-hydroxylase deficiency. Acta Obstet Gynecol Scand 2000; 79: 687-692 
[61] Hagenfeldt K, Janson PO, Holmdahl G et al. Fertility and pregnancy outcome in women with congenital adrenal hyperplasia due to 21-hydroxylase deficiency. Hum Reprod 2008; 23: 1607-1613

[62] Hoepffner W, Schulze E, Bennek J et al. Pregnancies in patients with congenital adrenal hyperplasia with complete or almost complete impairment of 21-hydroxylase activity. Fertil Steril 2004; 81: 1314-1321

[63] Bachelot A, Chakhtoura Z, Plu-Bureau G et al. Influence of hormonal control on LH pulsatility and secretion in women with classical congenital adrenal hyperplasia. Eur J Endocrinol 2012; 167: 499-505. doi:10.1530/EJE-12-0454

[64] Moran C, Azziz R, Weintrob N et al. Reproductive outcome of women with 21-hydroxylase-deficient nonclassic adrenal hyperplasia. J Clin Endocrinol Metab 2006; 91: 3451-3456

[65] Bidet M, Bellanne-Chantelot C, Galand-Portier MB et al. Fertility in women with nonclassical congenital adrenal hyperplasia due to 21-hydroxylase deficiency. J Clin Endocrinol Metab 2010; 95: 1182-1190

[66] Casteras A, De Silva P, Rumsby G et al. Reassessing fecundity in women with classical congenital adrenal hyperplasia (CAH): Normal pregnancy rate but reduced fertility rate. Clin Endocrinol (Oxf) 2009; 70: 833-837

[67] Holmes-Walker D], Conway GS, Honour JW et al. Menstrual disturbance and hypersecretion of progesterone in women with congenital adrenal hyperplasia due to 21-hydroxylase deficiency. Clin Endocrinol (Oxf) 1995; 43: 291-296

[68] Ogilvie CM, Rumsby G, Kurzawinski T et al. Outcome of bilateral adrenalectomy in congenital adrenal hyperplasia: One unit's experience. Eur J Endocrinol 2006; 154: 405-408

[69] Meyer-Bahlburg HF, Dolezal C, Baker SW et al. Sexual orientation in women with classical or non-classical congenital adrenal hyperplasia as a function of degree of prenatal androgen excess. Arch Sex Behav 2008; 37: 85-99

[70] Wang LC, Poppas DP. Surgical outcomes and complications of reconstructive surgery in the female congenital adrenal hyperplasia patient: What every endocrinologist should know. J Steroid Biochem Mol Biol 2017; 165: 137-144. doi:10.1016/j.jsbmb.2016.03.021

[71] Sturm RM, Durbin-Johnson B, Kurzrock EA. Congenital adrenal hyperplasia: current surgical management at academic medical centers in the United States. J Urol 2015; 193: 1796-1801. doi:10.1016/j.juro.2014.11.008

[72] Mouriquand PD, Gorduza DB, Gay CL et al. Surgery in disorders of sex development (DSD) with a gender issue: If (why), when, and how? J Pediatr Urol 2016; 12: 139-149. doi:10.1016/j.jpurol.2016.04.001

[73] Reifsnyder JE, Stites J, Bernabe KJ et al. Nerve Sparing Clitoroplasty is an Option for Adolescent and Adult Female Patients with Congenital Adrenal Hyperplasia and Clitoral Pain following Prior Clitoral Recession or Incomplete Reduction. J Urol 2016; 195: 1270-1273. doi:10.1016/j. juro.2015.12.053

[74] Lesma A, Bocciardi A, Montorsi F et al. Passerini-glazel feminizing genitoplasty: Modifications in 17 years of experience with 82 cases. Eur Urol 2007; 52: 1638-1644. doi:10.1016/j.eururo.2007.02.068

[75] Nordenstrom A, Frisen L, Falhammar $\mathrm{H}$ et al. Sexual function and surgical outcome in women with congenital adrenal hyperplasia due to CYP21A2 deficiency: Clinical perspective and the patients' perception. J Clin Endocrinol Metab 2010; 95: 3633-3640

[76] Claahsen-van der Grinten HL, Hulsbergen-van de Kaa CA, Otten B]. Ovarian adrenal rest tissue in congenital adrenal hyperplasia-a patient report. J Pediatr Endocrinol Metab 2006; 19: 177-182

[77] Motlik K, Starka L. Adrenocortical tumour of the ovary. (A case report with particular stress upon morphological and biochemical findings). Neoplasma 1973; 20: 97-110
[78] Russo G, Paesano P, Taccagni G et al. Ovarian adrenal-like tissue in congenital adrenal hyperplasia. N Engl J Med 1998; 339: 853-854

[79] Luton JP, Clerc ], Paoli $V$ et al. [Bilateral Leydig cell tumor of the ovary in a woman with congenital adrenal hyperplasia. The first reported case]. Presse Med 1991; 20: 109-112

[80] Cabrera MS, Vogiatzi MG, New MI. Long term outcome in adult males with classic congenital adrenal hyperplasia. J Clin Endocrinol Metab 2001; 86: 3070-3078

[81] Stikkelbroeck NM, Otten B], Pasic A et al. High prevalence of testicular adrenal rest tumors, impaired spermatogenesis, and Leydig cell failure in adolescent and adult males with congenital adrenal hyperplasia. J Clin Endocrinol Metab 2001; 86: 5721-5728

[82] Martinez-Aguayo A, Rocha A, Rojas N et al. Testicular adrenal rest tumors and Leydig and Sertoli cell function in boys with classical congenital adrenal hyperplasia. J Clin Endocrinol Metab 2007; 92: 4583-4589

[83] Claahsen-van der Grinten HL, Sweep FC, Blickman JG et al. Prevalence of testicular adrenal rest tumours in male children with congenital adrenal hyperplasia due to 21-hydroxylase deficiency. Eur J Endocrinol 2007; 157: 339-344

[84] Claahsen-van der Grinten HL, Otten B], Sweep FC et al. Repeated successful induction of fertility after replacing hydrocortisone with dexamethasone in a patient with congenital adrenal hyperplasia and testicular adrenal rest tumors. Fertil Steril 2007; 88: 705 e705-705 e708

[85] Claahsen-van der Grinten HL, Otten BJ, Stikkelbroeck MM et al. Testicular adrenal rest tumours in congenital adrenal hyperplasia. Best Pract Res Clin Endocrinol Metab 2009; 23: 209-220

[86] Reisch N, Scherr M, Flade L et al. Total adrenal volume but not testicular adrenal rest tumor volume is associated with hormonal control in patients with 21-hydroxylase deficiency. J Clin Endocrinol Metab 2010; 95: 2065-2072

[87] Smeets EE, Span PN, van Herwaarden AE et al. Molecular characterization of testicular adrenal rest tumors in congenital adrenal hyperplasia: Lesions with both adrenocortical and Leydig cell features. J Clin Endocrinol Metab 2015; 100: E524-E530. doi:10.1210/jc.2014-2036

[88] Claahsen-van der Grinten HL, Otten B], Hermus AR et al. Testicular adrenal rest tumors in patients with congenital adrenal hyperplasia can cause severe testicular damage. Fertil Steril 2007; 92: 3674-3680

[89] Bry-Gauillard H, Cartes A, Young J. Mitotane for 21-hydroxylase deficiency in an infertile man. $N$ Engl J Med 2014; 371: 2042-2044. doi:10.1056/NEJMc1410041

[90] Rohayem J, Tuttelmann F, Mallidis C et al. Restoration of fertility by gonadotropin replacement in a man with hypogonadotropic azoospermia and testicular adrenal rest tumors due to untreated simple virilizing congenital adrenal hyperplasia. Eur J Endocrinol 2014; 170: K11-K17. doi:10.1530/EJE-13-0449

[91] King TF, Lee MC, Williamson EE et al. Experience in optimizing fertility outcomes in men with congenital adrenal hyperplasia due to 21 hydroxylase deficiency. Clin Endocrinol (Oxf) 2016; 84: 830-836. doi:10.1111/cen.13001

[92] Turcu AF, Mallappa A, Elman MS et al. 11-Oxygenated Androgens Are Biomarkers of Adrenal Volume and Testicular Adrenal Rest Tumors in 21-Hydroxylase Deficiency. J Clin Endocrinol Metab 2017; 102: 2701-2710. doi:10.1210/jc.2016-3989

[93] Nermoen I, Rorvik J, Holmedal SH et al. High frequency of adrenal myelolipomas and testicular adrenal rest tumours in adult Norwegian patients with classical congenital adrenal hyperplasia because of 21-hydroxylase deficiency. Clin Endocrinol (Oxf) 2011; 75: 753-759 